\title{
STEM education supported by virtual laboratory incorporated in self-directed learning process
}

\author{
Peter Trúchly ${ }^{*}$, Martin Medvecký*, \\ Pavol Podhradský*, Nour El Mawas
}

\begin{abstract}
Students education in various fields (such as science, technology, engineering, and mathematics) is constantly looking for ways and techniques on how to motivate students to learn, how to increase their engagement and how to increase the efficiency of knowledge acquisition. Information and communication technologies are developing at a very rapid speed and offer many new opportunities that could be used for such purposes. This paper focuses on virtual laboratory technologies that could be very helpful for these learning problems especially for subjects that lose the interest of young people. We have conducted two pilots at a Slovak secondary school and university to analyse the usability of self-directed learning applied to teach networking topics such as software-defined networking and network functions virtualisation. This learning approach was enhanced by a developed virtual lab and a set of self-tests. Knowledge tests and questionnaires have been used to investigate the impact of this self-directed virtual lab-based learning approach on students motivation to learn, feelings, satisfaction with learning approach and knowledge gain. The results showed that students appreciated the virtual laboratory for improving learning and their motivation to learn and their knowledge acquisition was noticeably improved when the virtual lab was included.

K e y w ord s: self-directed learning, virtual lab, SDN, NFV, knowledge gain, questionnaire
\end{abstract}

\section{Introduction}

Science, technology, engineering, and mathematics (STEM) are areas that are still losing interest in learning among young people. Therefore it is necessary to find solutions about how to motivate students at primary and secondary schools in order to choose a suitable field for their career [1]. New innovative pedagogical approaches such as problem, inquiry, project or game-based learning, flipped classrooms and computer-supported collaborative learning have been proposed and investigated in various studies [2-4]. Modern information and communication technologies can also strengthen these pedagogical approaches and make easier the study and understanding STEM problems. Virtual and augmented reality applications, multimedia and mulsemedia applications, virtual and real laboratories are new trends that can help to engage students in STEM fields and help them to imagine and understand difficult and abstract problems.

Virtual lab technology provides several benefits for students as well as teachers [5]. They represent a costefficient way for the organisation of laboratory work in the STEM field. They are flexible and provide students with variability of experiments that can be done by many students independently and at the same time. Possible and easy configuration and damage resistance are other benefits [6]. Although they have also some drawbacks in comparison with real labs (eg they are virtual so students can show lack of seriousness, responsibility, and carefulness) their potential for STEM education is high and must be investigated in various STEM disciplines in conjunction with suitable pedagogical approaches. Self-directed learning (SDL) belongs to new trends in education but puts higher demands on students motivation and responsibility in learning and is also a subject of various studies $[7,8]$. Therefore we decided to develop a virtual lab for the networking field and integrate it with self-directed learning and investigate how this concept influences students knowledge acquisition as well as their attitude (motivation and engagement) to learn.

We carried out our research studies in the framework of a large-scale EU Horizon 2020 project called Newton [9]. This project is focused on the development, integration, deployment, and dissemination of state-of-the-art technology-enhanced learning methodologies (such as virtual/augmented reality, multimedia, mulsemedia, interconnected fabrication labs, virtual lab technologies, gamification, and self-directed learning).

\section{Related works}

During the last decade, significant evolution was observed in the area of virtual and remote labs and their deployment in learning and training processes. There are several studies dealing with summarization and comparison of existing virtual labs in the world such as $[6,10,11]$.

*Slovak University of Technology, Bratislava, Slovakia, peter.truchly@stuba.sk, martin.medvecky@stuba.sk, pavol.podhradsky@stuba.sk, **CIREL(EA 4354), University of Lille, Lille, France, nour.el-mawas@univ-lille.fr 
Since there are two options on how to access lab resources and services as well as there are two options how lab experiments correspond to real processes we can distinguish four types of lab environments $[11,12]$ :

- real local labs - can be called as traditional (handson) labs; students are physically dealing with real lab resources, apparatuses, and experiments,

- real remote labs - students connect remotely via internet to the real lab environments using an experimentation interface,

- virtual local labs - these labs run locally as some kind of a program, software or application which allow students to perform simulated or emulated experiments,

- virtual remote labs - students remotely connect to the virtual lab environment situated on a server in a cloud or data centre using an experimentation interface.

Traditional labs allow students to touch/experience real/physical systems, devices, and resources via experiments but are related to high costs of equipment, space, and maintenance [12]. On the other hand, virtual labs solve those limitations and can be easily shared between students, set up, used and maintained at considerably lower costs [10]. Because of these and other advantages, virtual labs have recently gained popularity and consequently, many various labs have been developed.

The virtual local labs can be implemented and provided in two ways (a desktop application and web-based application) [11]. Desktop applications are less portable (they are OS/platform dependent) and less secure (eg admin rights needed for installation). They require a desktop computer, laptop, tablet, smartphone or smart TV. New trends investigate including a virtual reality (VR) applications via some VR glasses [13] or even tactile and olfaction feedback [14] via special hardware. The webbased applications can be provided on multiple platforms but a web browser is required to run. This type of application is also used for the virtual (often real as well) remote labs which are based on the client-server architecture. This type of virtual lab representation is suitable for complex experiments requiring high computational power. Virtual labs are mostly used within the learning process and therefore it is useful to integrate them with some learning management system (LMS, eg Moodle) or remote laboratory management system (RLMS, eg iLab $[15])$.

Currently, there are virtual labs oriented to various STEM domains such as physics, robotics, engineering, electronics, automatic control, probability, statistics, networking, etc. Virtual and remote labs are usually developed by universities often within international projects with partner institutions and companies. Selected examples are briefly presented below. Digital fabrication laboratory (FabLab) based at CEU University in Madrid [16] can be mentioned as one of the representatives for the local real labs where students can work with digital fabrication tools and learn to produce innovative articles. Examples of real remote labs can be Labshare [17] and LRA
[18]. The Labshare institute provides a suite of remote labs teaching dynamics, mechanics, field-programmable gate arrays, robotics, power systems, signal measurement, and others. The LRA (remote laboratory of automatic control) offers labs in automatic control. Note that Labshare and LRA are not free.

Furthermore, there were projects funded by the European commission such as GoLab [19], LiLa [20] and VccSSe [21] developing virtual labs and platform/portal to share them. In addition to many virtual labs first two projects also integrated several remotely operated real labs. Many virtual and remote (real) labs are also maintained by the UNILabs network [22]. REX Controls offer virtual labs [23] which are free and based on Java runtime environment and covering controllers and control. They also provide their own lab development tool called REXYGEN.

In order to improve students understanding and interactivity, many labs are based on some 3D graphic interface and models [24] such as the web-based 3D virtual fabrication lab VirtualCVD Reactor [25]. Furthermore, many $3 \mathrm{D}$ virtual labs are oriented to rapidly developing robotics (such as RoboUALab [26] or VCIMLAB [27]) allowing students to learn how to program, control and operate robots that can be used in industry, medicine, dangerous workplaces, etc. Lately, augmented reality [28] and virtual reality (VR) have gained popularity because the necessary gear is not more expensive and inaccessible. That is why studies investigating and comparing VR enhanced virtual labs with standard virtual labs start to appear $[13,29]$. To support game-based learning various VR applications have also been developed [30,31]. When we concentrate on labs and experiments in a networking domain we can use physical labs, network simulators, virtualized application labs, shared host labs, single or multiple virtual machine (VM) labs [32]. There are many widely used network simulators such as ns-2, ns-3, OPNET, OMNeT++, QualNet, NetSim, Packet Tracer, and Mininet [33] that can be used locally or remotely. Labs based on virtual machines can also be installed on a students PC or in the cloud. V-Lab [34], NVLab [35] and VLabNet [36] represent examples of such labs. Virtual Box, VMware, KVM, and Xen are the most often used virtualisation software. Except for (client-based) GNS3 to create a complex virtual networking lab, it is possible to use for example paid client based VIRL [37] or free clientless EVE-NG [38].

Many empirical studies have been carried out to analyse how virtual labs influence students motivation to learn and the effectiveness of knowledge acquisition [11]. Brinson [39] analysed 56 papers (empirical studies) oriented to a comparison of results achieved by traditional labs and virtual labs. $62.5 \%$ of those papers showed higher learning outcomes for virtual labs, $21.4 \%$ presented the same level of learning outcomes for both lab types and in only $8.5 \%$ of papers traditional labs taught students more than virtual labs. Authors in [40] realised a meta-analysis of 69 studies (8432 learners) covering the 


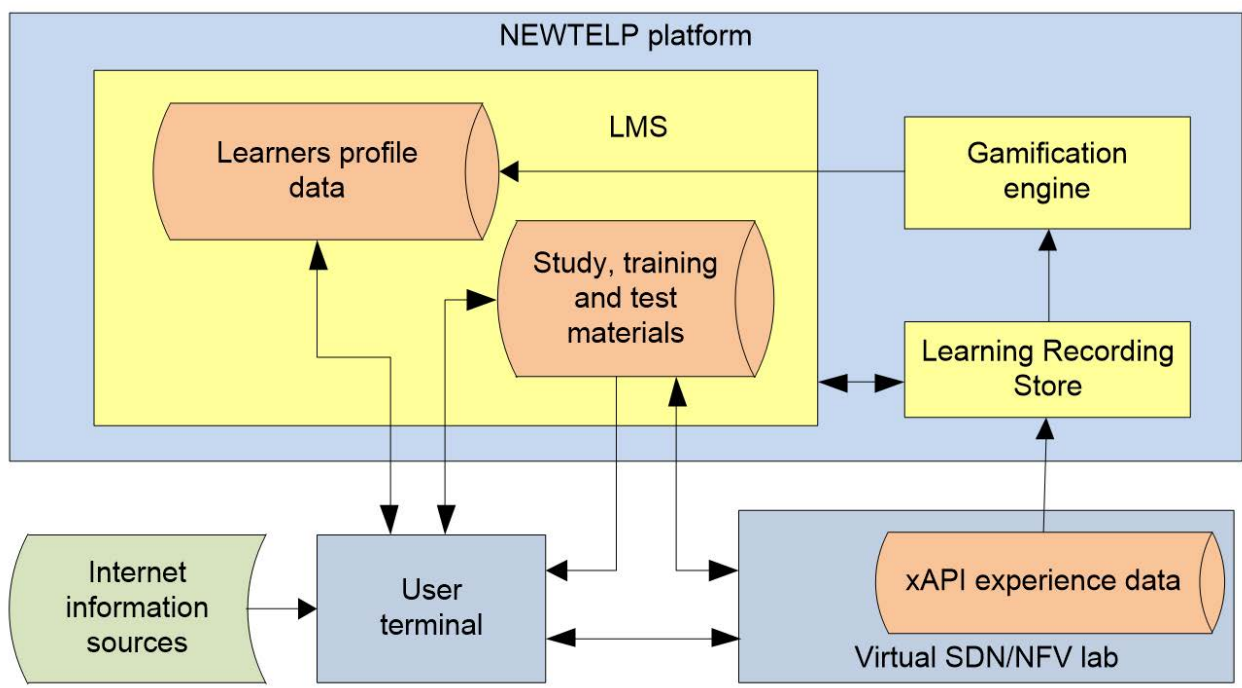

Fig. 1. Functional view of the learning system

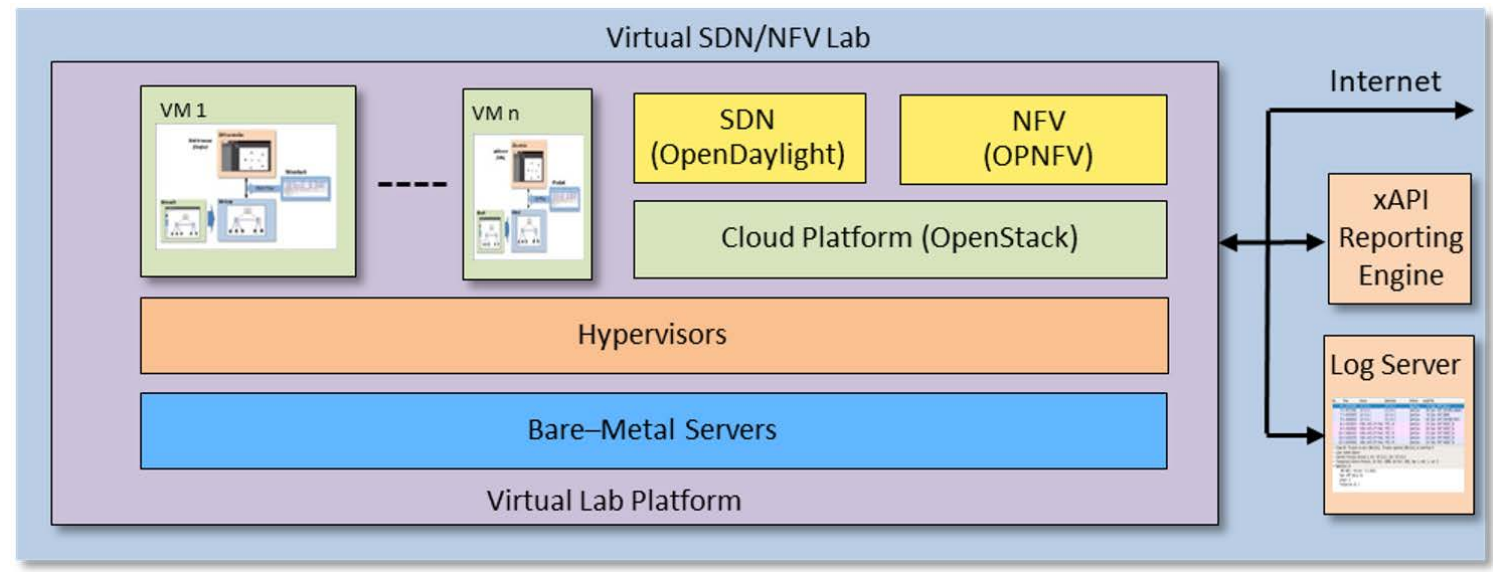

Fig. 2. Virtual SDN/NFV lab block diagram

deployment of virtual reality instruction (games, simulations and virtual worlds) in K-12 and higher education. The results of this meta-analysis show that VR based learning has numerous advantages and provides a means to improve learning outcomes.

There are also some studies analysing the benefits of virtual labs allowing students to make networking experiments. For example, authors of NVLab [35] tested their lab on a sample of 15 learners and achieved positive feedback from learners as well as a positive knowledge gain. In the case of the V-Lab study [34], 250 students have been involved in testing and questionnaire results showed satisfactory feedback from students. Moreover, this lab helps students to understand and practice networking problems. WeFiLab presented in [41] was evaluated by 315 students. The study showed more than $70 \%$ satisfaction of students with the lab.
As was mentioned, virtual labs provide many advantages and they are very positively accepted by students. There are also some studies investigating the benefits of virtual labs in networking subjects but their number is very low and they especially focus on questionnairebased students feedback on satisfaction aspects. Investigating the impact of virtual labs on knowledge acquisition is still not sufficient. Many studies concentrate on virtual lab usage and perception by students but they do not analyse how to include these labs in the educational process in conjunction with new pedagogical approaches such as self-directed learning. Therefore, we decided to develop a virtual lab for training new networking technologies (software-defined networking and network functions virtualisation), integrate it with SDL and investigate how this approach influences students knowledge acquisition, motivation, satisfaction and usability at various (school) levels. Although, there are also commercial 


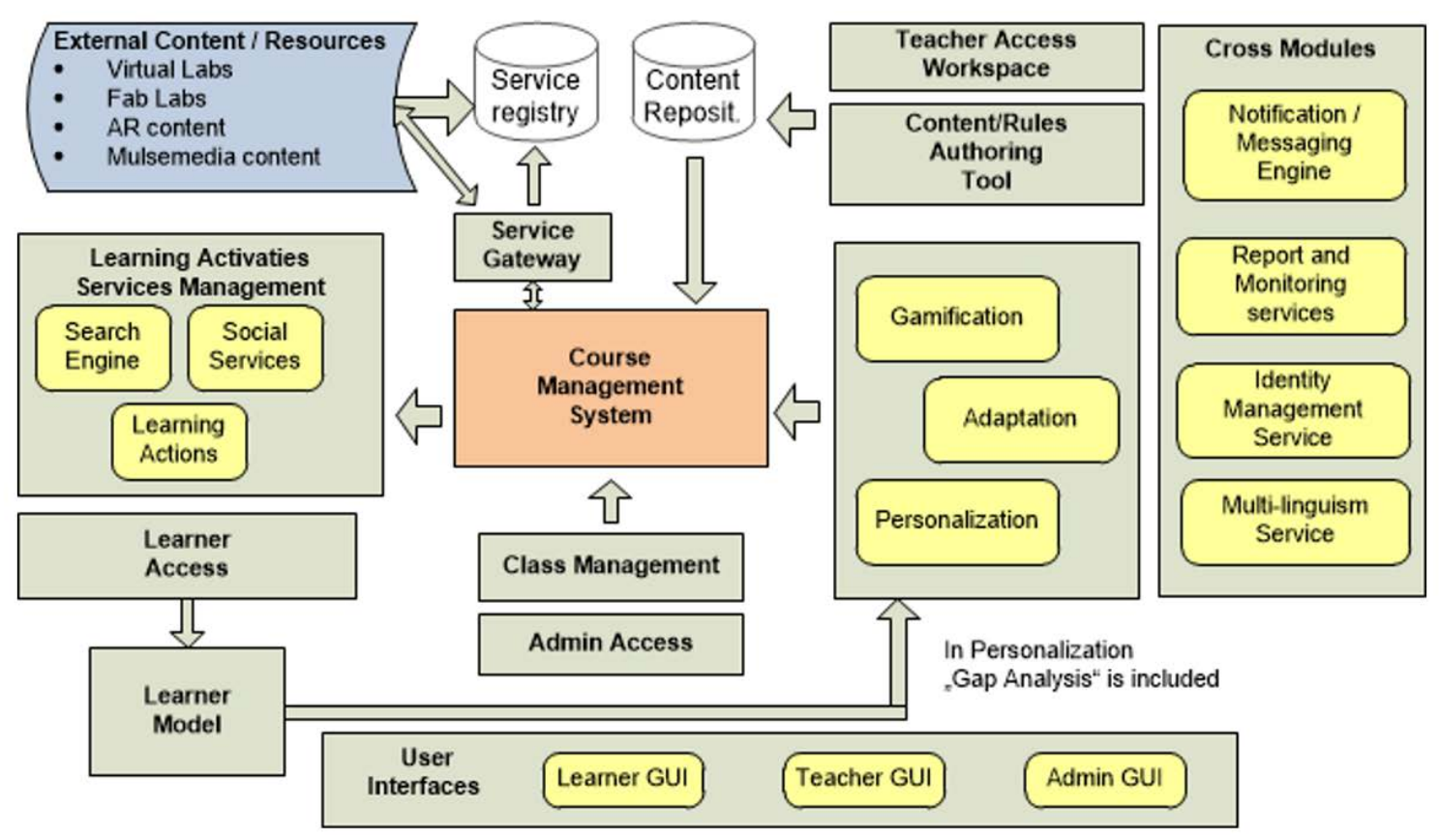

Fig. 3. NEWTELP platform-functional architecture

courses (including labs) available online, powered by the Linux Foundation and oriented to this field of networking they are too large for our purpose, difficult to integrate with our system and mostly paid.

\section{Learning system description}

The learning system used in our project consisted of two main parts: the virtual SDN/NFV laboratory and the NEWTELP learning platform (see Fig. 1) [9]. Although both parts of the learning system can be used independently, they have been integrated with each other, allowing students to increase their learning potential and to use the Virtual SDN/NFV laboratory for self-directed learning.

\subsection{Virtual SDN/NFV lab}

The virtual SDN/NFV lab is a virtual remote laboratory created at FEI STU in Bratislava. The virtual laboratory was designed to support teaching and research activities in the fields of software-defined networking (SDN) and network function virtualization (NFV). The laboratory's main goal is to enable students and researchers to access state-of-the-art SDN and NFV technologies using software applications with high hardware demand.

The virtual SDN/NFV lab uses virtualization and cloud computing and it is built mainly on bare-metal servers, hypervisors, and the OpenStack cloud platform. The block diagram of the Virtual SDN/NFV lab is shown in Fig. 2.

The virtual lab infrastructure is proposed to emulate several OPNFV (open platform for NFV) tenants and to run tens of virtual machines (VM). The virtual lab servers are interconnected via VLAN-enabled Ethernet switches, allowing the creation of four separate networks (internet, management network, instance network, and storage network). In addition to these cloud networks, software-defined networks are created on-demand using virtual open virtual switches (vSwitch) provided by the virtualization platform. The connection to the internet is provided by the router. For the purpose of monitoring and evaluating student activity while working in the lab, a $\log$ server and xAPI reporting engine were integrated into the virtual laboratory. A more detailed description of the architecture and implementation of the SDN/NFV lab can be found in [42].

\subsection{Learning management platform}

As a learning management platform, the NEWTELP platform was used. The NEWTELP platform, created as a part of the European project NEWTON, is based upon a multi-tier, client-server architecture and currently interconnects several existing state-of-the-art pan-European teaching labs. The benefits of the NEWTELP platform are that it separates centrally held data, client access technology, and business logic into separate layers using standard open interfaces. To prevent unauthorized access, the NEWTELP platform has implemented a securely managed interface to isolate systems from illegal access. The functional architecture of the NEWTELP platform is shown in Fig. 3 .

The course management system (CMS) is the main component of the NEWTELP platform and acts as a coordinator for all the functions provided by the system. 


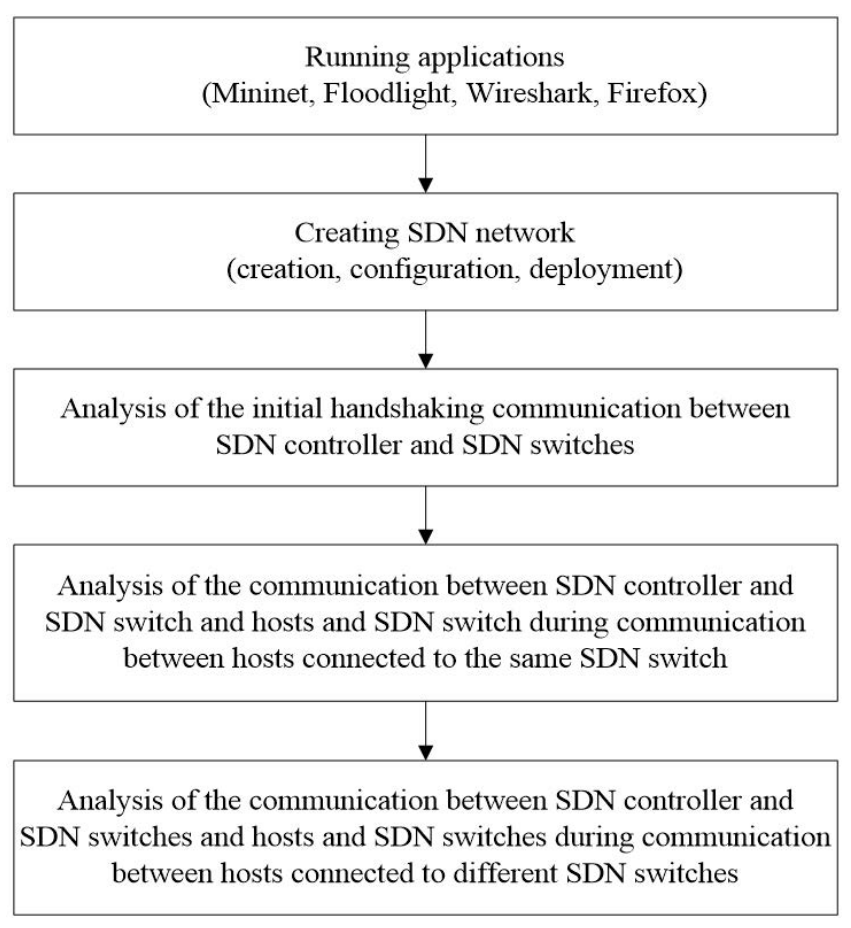

Fig. 4. Tasks in learning scenario (SDN OpenFlow tasks)

The CMS collects and integrates most of the content and services created in the learning and teaching process and serves as a hub for different components of the platform.

The platform contains three sub-modules: gamification, personalisation, and adaptation. The personalisation sub-component encourages learners to achieve the learning objectives of the course. It is done by identifying learners' needs and recommending a set of relevant content to address their knowledge gap. The adaptation subcomponent provides content adaptation to the learners when multimedia and mulsemedia educational contents are delivered. The gamification sub-component provides a gamification/reward element configuration. The gamification sub-component interacts with the CMS.

The Virtual SDN/NFV lab was integrated into the NEWTELP platform as a virtual lab as shown in Fig. 1 [43]. The main component involved in integration is the xAPI Reporting Engine. All activity reports transmitted from the Virtual SDN/NFV lab to the NEWTELP platform are transmitted as xAPI statements using predefined xAPI verbs. Statements contain time information, evaluation of the activity and mapping to a particular course. The xAPI Reporting Engine scans the learners activities logged in the Virtual SDN/NFV lab and updates his reporting database. It maintains the authorization information (obtained from learning recording store (LRS) subsystems) and course mapping information (schedule and user-based) as well. According to the configuration, the experience data can be reported immediately to the LRS using the xAPI or buffered. The buffering mechanism allows validating the data by the trainer before reporting them to the platform. A detailed description of the integration of the SDN/NFV lab with the NEWTELP platform was proposed in [43].

\subsection{Learning scenario}

For the purpose of this study, one of the basic scenarios developed for work in the virtual SDN/NFV lab was chosen. In this scenario, students can verify their knowledge of the OpenFlow protocol with the experience gained in monitoring and analysing real communication between the SDN controller and SDN switches. Each student had his own virtual testbed (virtual machine with 2 CPUs, 4 GB RAM and Linux Ubuntu 16.04 LTS) which included an SDN controller Floodlight, an SDN network emulator Mininet, and other preinstalled programs such as Wireshark to capture and analyse network communications and a web browser Firefox to display internal SDN controller status (network topology and SDN switch flow tables). The required number of instances (VMs) was created for each test group (up to $30 \mathrm{VMs}$ ). Each student has configured and analysed his own SDN network deployed in his own virtual environment (VM) and his activities were recorded locally on the particular virtual server and on the central virtual SDN/NFV lab log server. Processed activities were transferred to the reporting data storage of the xAPI reporting engine and also to the NEWTELP platform.

The students followed the pre-prepared scenario while performing a set of tasks that were subdivided into individual steps (see Fig. 4). Each task logically followed each other, with each task forming a complex whole. In addition to the scenario itself, the student also had a worksheet in which he wrote down various data, such as device addresses, OpenFlow messages, etc.

While working on lab tasks, students use a standard, well-known Linux user interface when individual applications are opened in separate windows that students can organize as needed. The fulfilment of the scenario, as well as its individual parts, can be monitored and evaluated according to the worksheet elaborated by a student as well as through different records such as logs on VMs, logs on the central server, a file containing the SDN network created by student stored on the VM and so on. Some of this information has been used to report via xAPI to the NEWTEL platform, others to test and verify the obtained results.

\section{Research studies}

Research studies we carried out in the framework of the Horizon 2020 NEWTON project incorporated virtual lab based on a pedagogical approach. We investigated how this approach influences knowledge acquisition when compared with the classical pedagogical approach. We also analysed how learners motivation to learn and satisfaction with the learning process are affected at two levels of education (secondary school and university). 

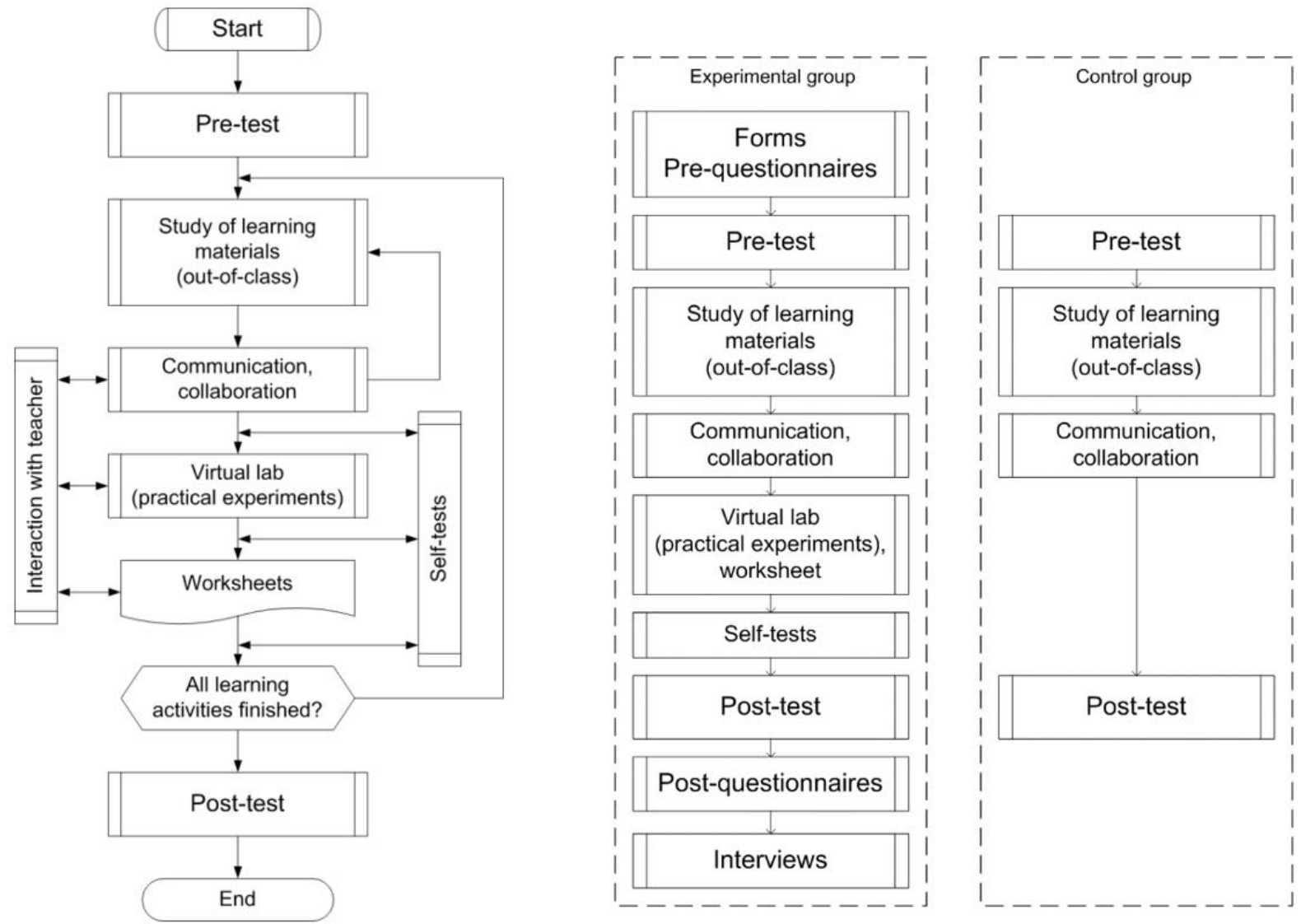

Fig. 5. Learning process scheme based on self-directed learning and virtual lab used in our studies

\subsection{Learning research methodology}

The pedagogical approach applied in our research studies was based on the integration of two technologies: virtual labs and self-directed learning. As we can see in Fig. 5 learning process contained several phases. In order to evaluate knowledge acquisition of learners, we included pre and post tests (in the beginning and at the end of pilots, respectively). Once the pre-test was completed, learners started to study learning materials either remotely at the project platform (NEWTELP) or locally after downloading the materials to their computers. During this phase, learners could discuss with each other or communicate with a teacher to better understand a subject. Following this out-of-class part, the learners worked remotely inside a virtual lab to do practical experiments with the teacher who led this phase. The students were also able to work out some worksheets. To allow learners to test their knowledge a set of self-tests were available which could be carried out during the entire learning process and even repeatedly. However, it was recommended to take these tests after the study of learning materials. When all learning activities were finished students took a final test (post-test) and the course was completed.

To compare the efficiency of our new pedagogical approach to a classical approach, we also realised the same course based on self-directed learning but without virtual lab experiments and self-tests. A group of students who
Fig. 6. Comparison of learning processes for both groups of students (experimental as well as control)

experienced our proposed pedagogical approach (ie selfdirected learning with virtual lab and self-tests) we refer to as an experimental group (EG). Students who took part in the self-directed learning process with only access to electronic study/learning materials (with the ability to communicate with classmates and a teacher) belonged to a control group (CG). Figure 6 sketches these differences. Both groups took the same pre-test as well as the same post-test. Both tests consisted of 7 single choice questions so they could be quickly completed. Pre-test and post-test questions were designed to test the same knowledge but a formulation of questions was different. Based on pre-and post-test results a knowledge gain was calculated for the final evaluation of studies.

As can be seen from Fig. 6 students of the experimental group had to sign some forms and complete a set of questionnaires. During the pilot introduction students (and teachers) participating in this research study signed assent forms, a data management plan, and a plain language statement. To be able to evaluate students motivation, satisfaction with learning, attitude to learning STEM and pilot usability learners completed two questionnaires (demographic and motivation) prior to and two other questionnaires (motivation, usability) after the learning part (phases). Moreover, some of the learners were asked to take part in interviews at the end of the pilot. 


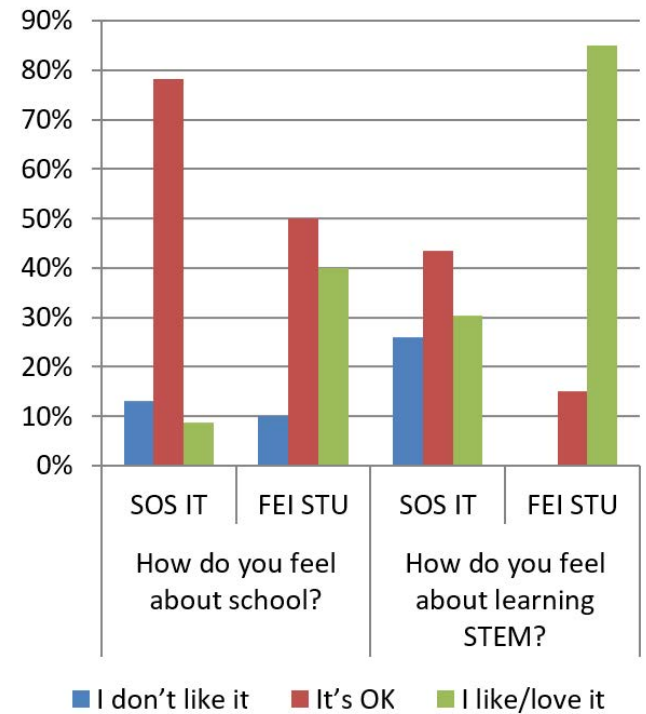

Fig. 7. Attitude to school and learning STEM for students from SOS IT and FEI STU

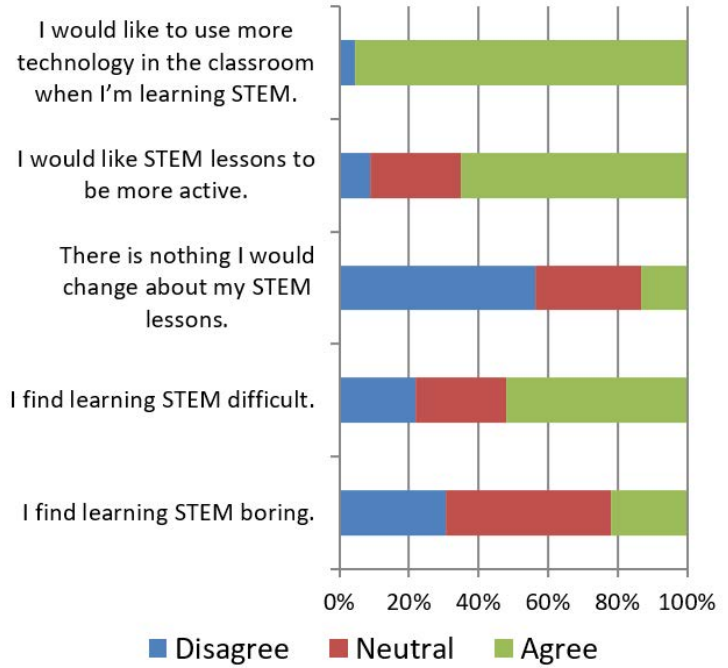

Fig. 8. Results for questionnaire questions/statements about learning STEM

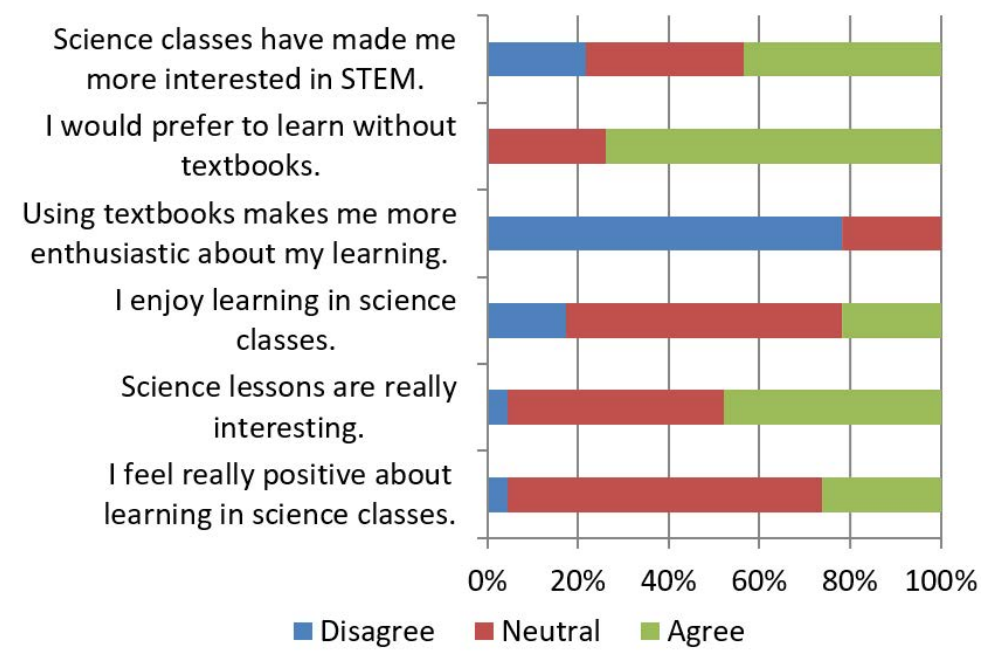

Fig. 9. Questionnaire results for selected student satisfaction questions at SOS IT in BB

\subsection{Secondary level school participants}

One of the pilots investigating the virtual lab-based learning approach was realised in the Vocational school of Information Technologies (SOS IT) in Banská Bystrica (BB), Slovakia. This school is very open to employing new technologies as part of teaching. Two 3rd grade classes from this school were involved in this pilot. One class of students took part as the experimental group and the other one as the control group. Students were between 15 and 18 years old. The experimental group contained 23 students and the control group contained 30 students.

Using demographic questionnaires (answered in the beginning) we can analyse students feelings in relation to school and learning STEM subjects. Based on Fig. 7 we can see that the majority of students $(78 \%)$ at this secondary school (SOS IT BB) said It is OK to study in that school and only 3 students said they did not like it and 2 students liked it. With respect to feeling about learning STEM $26 \%$ of students said they do not like it while the rest of the students like or love it or said It is OK.

The results for other questions in the questionnaire are shown in Fig. 9. We can see that the majority of students $(95 \%)$ of the EG from this school would like to use more technology during learning STEM and $65 \%$ of students would like to have STEM lessons more active. More than half of students would like to change their STEM lessons and they think that learning STEM is difficult but only about $22 \%$ find it boring.

The results for another set of questions (statements) asked students within questionnaires are depicted in Fig. 9. $74 \%$ of students would like to learn without textbooks and $78 \%$ are not very enthusiastic about using them in learning. Although less than half of students see 


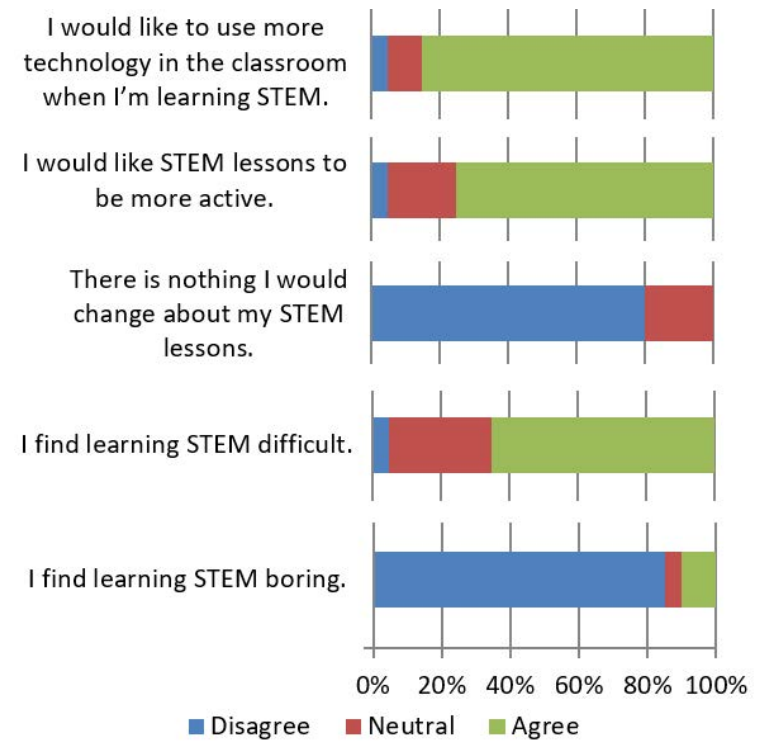

Fig. 10. Results for questionnaire questions about learning STEM at FEI STU

science lessons interesting only $21 \%$ to $26 \%$ of students enjoy learning in science classes and feel really positive about it. On the other hand, more than $60 \%$ of students have a neutral attitude in these cases.

\subsection{Tertiary level school participants}

The second pilot focused on the same research goals was realised at the Faculty of Electrical Engineering and Information Technology of Slovak University of Technology (FEI STU) in Bratislava, Slovakia. The experimental group of students was only included in this pilot. This group consisted of 20 students.

Based on Fig. 7 it is possible to see that $40 \%$ of students (at FEI STU) like or love their university and $85 \%$ of students like/love learning STEM. In comparison with the sample from the secondary school (SOS IT), we can see an increase of $30 \%$ (for those who like/love the school) and $55 \%$ (for those who like/love learning STEM). This result is expected because students choosing a university to study are more mature and have a clearer idea of what they want and need than students applying for secondary schools.

Concerning the university students attitude to learning STEM (see Fig. 10 for results) $85 \%$ of students would like to have more technologies in the classrooms what is a slight decline when compared to results from SOS IT but university students usually experience more technologies during their lessons. $75 \%$ of students still require lessons to be more active and $80 \%$ of students would like to change their STEM lessons (it is the increase in both cases when compared to SOS IT). Only $5 \%$ of students find learning STEM difficult (against $22 \%$ at SOS IT) and boredom in learning STEM is only felt by $10 \%$ of FEI STU students (against $30 \%$ at SOS IT).

Figure 11 visualizes results for questions related to student satisfaction questionnaire. It is expected that uni-

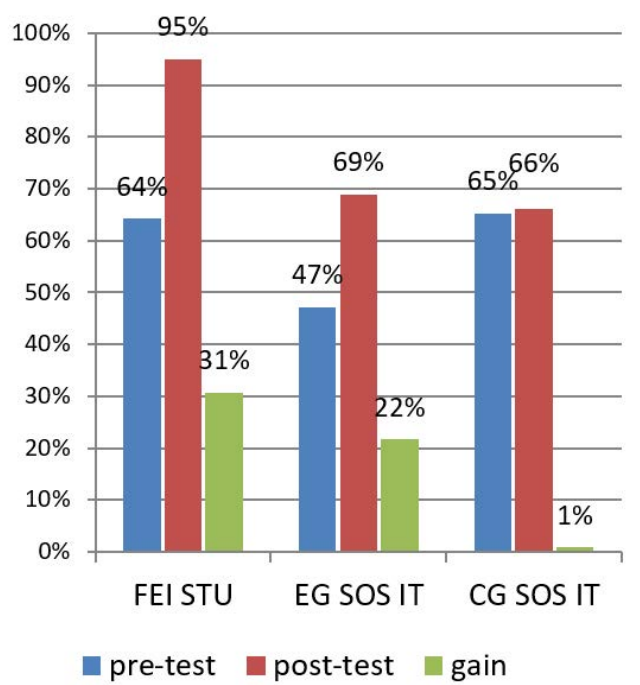

Fig. 11. Questionnaire results for selected student satisfaction questions at FEI STU

versity students should be more interested in STEM. It is confirmed by $85 \%$ of students who agreed. It represents an increase of $41 \%$ against SOS IT. Very similar results are acquired for the statement that science lessons are interesting. On the other hand, university students realise that textbooks are important sources of information in learning so there are some (FEI STU) students who would not prefer to learn without them. $60 \%$ of students (against $22 \%$ at SOS IT) enjoy learning in science classes. $60 \%$ of university students feel really positive about learning in science classes (against $26 \%$ at SOS IT).

\section{Results analysis}

In this section, we evaluate students knowledge acquisition in terms of knowledge gain, the impact of the new pedagogical virtual lab-based approach on students attitudes to learning STEM and results based on subgrouping analysis.

\subsection{Knowledge acquisition}

Knowledge acquisition is evaluated based on the results of pre-and post-tests and knowledge gain as a difference (improvement) between pre- and post-test average scores. The results are depicted in Fig. 12 for both groups (experimental and control) from SOS IT and the experimental group from FEI STU. It can be seen that both experimental groups after using virtual labs achieved positive improvements (knowledge gains) that are statistically significant (for paired t-tests for means with $\alpha=0.05$ ). The control group achieved statistically insignificant improvement and it shows that the selfd-directed learning approach based on only study materials is not usable by secondary level students which are not so motivated and responsible to learn in their spare time. On the other 


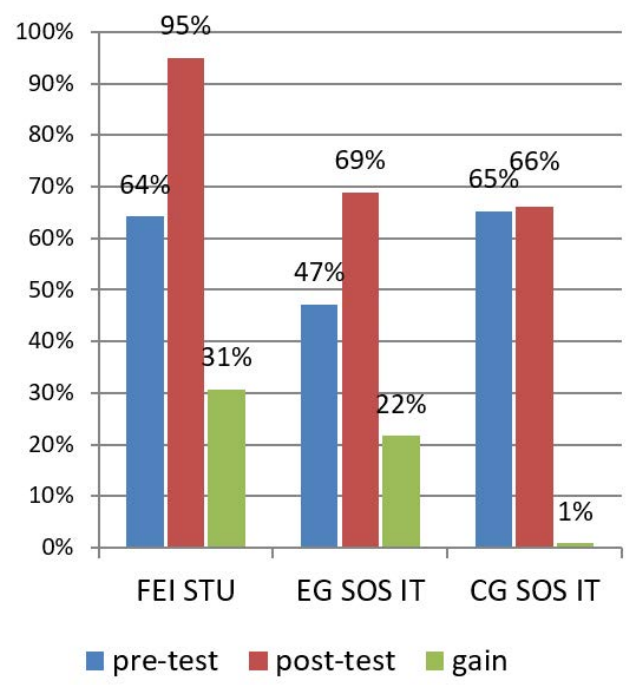

Fig. 12. Pre-and post-test average scores and knowledge gain

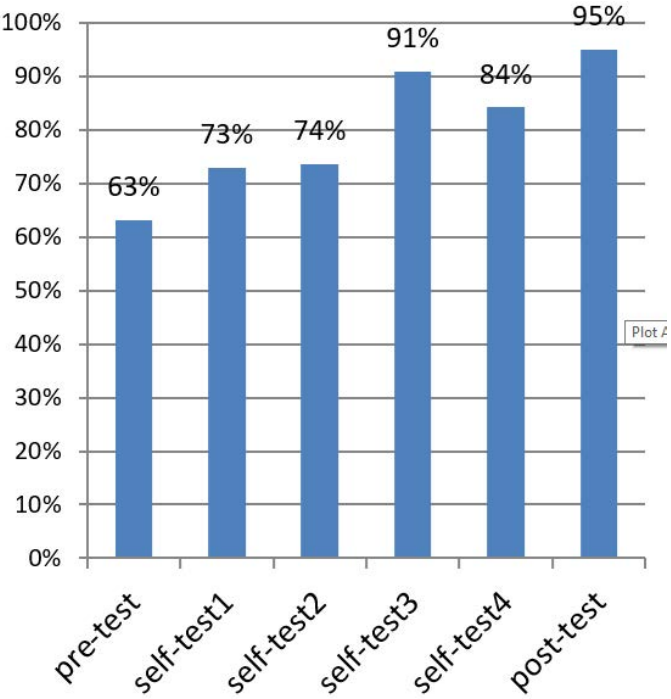

Fig. 13. Average scores for all knowledge tests (students who took all self-tests)

Table 1. Differences for pre-and post-questionnaire question results

\begin{tabular}{|c|c|c|c|c|c|c|c|}
\hline \multirow{2}{*}{\multicolumn{2}{|c|}{ Question }} & \multicolumn{2}{|c|}{ FEI STU } & \multicolumn{2}{|c|}{ SOS IT-related } & \multicolumn{2}{|c|}{ SOS IT-overall } \\
\hline & & diff. $(\%)$ & $\mathrm{p}$ value & diff. & $\mathrm{p}$ value & diff.( $\%)$ & $\mathrm{p}$ value \\
\hline \multicolumn{2}{|l|}{ Interest in science classes } & -8.42 & 0.01 & $\mathrm{n} / \mathrm{a}$ & $\mathrm{n} / \mathrm{a}$ & 7.83 & 0.07 \\
\hline \multicolumn{2}{|c|}{ Confidence about solving problems in classes } & -2.22 & 0.49 & $\mathrm{n} / \mathrm{a}$ & $\mathrm{n} / \mathrm{a}$ & 10.43 & 0.07 \\
\hline \multirow{8}{*}{$\begin{array}{l}\text { While you were learning in } \\
\text { your science class, to what } \\
\text { extent did you feel the } \\
\text { following? }\end{array}$} & Engagement & 7.00 & 0.13 & $\mathrm{n} / \mathrm{a}$ & $\mathrm{n} / \mathrm{a}$ & 20.00 & - \\
\hline & Anxiety & -6.32 & 0.25 & $\mathrm{n} / \mathrm{a}$ & $\mathrm{n} / \mathrm{a}$ & -0.91 & 0.84 \\
\hline & Boredom & -12.00 & 0.02 & $\mathrm{n} / \mathrm{a}$ & $\mathrm{n} / \mathrm{a}$ & -10.00 & 0.08 \\
\hline & Relaxation & 17.00 & - & $\mathrm{n} / \mathrm{a}$ & $\mathrm{n} / \mathrm{a}$ & 11.82 & 0.06 \\
\hline & Sadness & -4.44 & 0.50 & $\mathrm{n} / \mathrm{a}$ & $\mathrm{n} / \mathrm{a}$ & 1.82 & 0.70 \\
\hline & Happiness & 14.74 & - & $\mathrm{n} / \mathrm{a}$ & $\mathrm{n} / \mathrm{a}$ & 13.64 & - \\
\hline & Anger & -8.42 & 0.23 & $\mathrm{n} / \mathrm{a}$ & $\mathrm{n} / \mathrm{a}$ & 2.73 & 0.66 \\
\hline & Enjoyment & -5.00 & 0.30 & $\mathrm{n} / \mathrm{a}$ & $\mathrm{n} / \mathrm{a}$ & 8.70 & 0.06 \\
\hline \multicolumn{2}{|c|}{ I feel really positive about learning in classes } & 3.16 & 0.49 & $\mathrm{n} / \mathrm{a}$ & $\mathrm{n} / \mathrm{a}$ & 3.64 & 0.29 \\
\hline \multicolumn{2}{|c|}{ Science/NEWTON lessons are really interesting } & -8.00 & 0.02 & -8.70 & - & 1.74 & 0.69 \\
\hline \multicolumn{2}{|c|}{ I enjoyed learning in science classes } & 3.00 & 0.48 & $\mathrm{n} / \mathrm{a}$ & $\mathrm{n} / \mathrm{a}$ & 6.36 & 0.27 \\
\hline \multicolumn{2}{|c|}{$\begin{array}{l}\text { Using NEWTON makes me more } \\
\text { enthusiastic about my learning }\end{array}$} & 29.00 & - & $\mathrm{n} / \mathrm{a}$ & $\mathrm{n} / \mathrm{a}$ & 20.00 & - \\
\hline \multicolumn{2}{|c|}{$\begin{array}{l}\text { I would prefer to learn without textbooks } \\
\text { /NEWTON }\end{array}$} & -17.00 & 0.03 & -20.00 & - & -30.43 & - \\
\hline \multicolumn{2}{|c|}{$\begin{array}{l}\text { Science/NEWTON classes have made me } \\
\text { more interested in STEM }\end{array}$} & -13.00 & - & -12.45 & - & -1.74 & 0.77 \\
\hline I find learning STEM & $\begin{array}{l}\text { boring } \\
\text { difficult }\end{array}$ & $\begin{array}{c}3.00 \\
-14.00\end{array}$ & $\begin{array}{c}0.62 \\
-\end{array}$ & $\begin{array}{c}-1.74 \\
\mathrm{n} / \mathrm{a}\end{array}$ & $\begin{array}{c}0.69 \\
\mathrm{n} / \mathrm{a}\end{array}$ & $\begin{array}{l}6.09 \\
4.35\end{array}$ & $\begin{array}{l}0.20 \\
0.39\end{array}$ \\
\hline \multicolumn{2}{|c|}{$\begin{array}{l}\text { There is nothing I would chnage about } \\
\text { my STEM lessons }\end{array}$} & 7.00 & 0.05 & $\mathrm{n} / \mathrm{a}$ & $\mathrm{n} / \mathrm{a}$ & 1.74 & 0.73 \\
\hline \multicolumn{2}{|c|}{ I would like STEM lessons to be more active } & 8.00 & 0.028 & $\mathrm{n} / \mathrm{a}$ & $\mathrm{n} / \mathrm{a}$ & -8.70 & 0.08 \\
\hline \multicolumn{2}{|c|}{$\begin{array}{l}\text { I would like to use more technology in the } \\
\text { classroom when I am learning STEM }\end{array}$} & 2.00 & 0.67 & $\mathrm{n} / \mathrm{a}$ & $\mathrm{n} / \mathrm{a}$ & -20.00 & - \\
\hline
\end{tabular}

- less than 0.01

hand, when such an approach is enhanced by some active elements such as virtual labs, knowledge acquisition is positively supported and increased. Tertiary students (at FEI STU) reported higher improvement (31\% against $22 \%$ ). Students at this level are used to study at their spare time (self-study), are more motivated to study STEM and they are even in many cases able to work in virtual labs remotely (out of class) using guides and as- 
signment whereas secondary level students need presence of a teacher (in class) to introduce them a concept of the virtual SDN/NFV lab and help them with initial steps and problems.

Due to some reasons (such as some instabilities of LMS platform (testing phase) during case study at SOS IT, taking tests by students remotely (in their spare time) and self-directed learning concept) only a very few secondary students took self-tests. Therefore, we can evaluate self-test results only for students from FEI STU where those problems were not present or related. Figure 15 shows average scores for all knowledge tests (pre, self1, , self4 and post) for those students who took all self-tests. We can see only one score (for self-test3) which breaks the ascending trend in scores. To maintain the ascending level (difficulty) of self-tests it should be probably suitable to change the order of self-test 3 and self-test 4 .

\subsection{Questionnaire results evaluation}

As was already mentioned students of the experimental groups took questionnaires before (pre) and after (post) research studies (pilots) when a Likert-type scale was applied. These questionnaires contained paired questions or statements which allowed us to evaluate how students attitude and feelings changed during and after pilots.

Table 1 summarises questionnaire results in terms of a difference (diff.) between pre-and post-questionnaire question average scores. The columns with $\mathrm{p}$ values come from paired t-test for means. Statistically significant results (differences) are highlighted in Tab. 1 (when $\alpha=$ 0.05 is considered). The FEI STU pilot contained only one lesson. The pilot at SOS IT contained three various lessons two of them testing the virtual reality applications incorporated in the learning process (some results can be found in [30]) and the third one was based on our virtual SDN/NFV lab. In such bigger pilots we did not want to overload students with long questionnaires (after each lesson) therefore we asked students to take only a reduced version. That is why we only have results for four questions directly related to the virtual SDN/NFV lab study/lesson (SOS IT related column in Tab. 1). However, we also included overall results for the entire pilot the virtual SDN/NFV lab study was included in (SOS IT overall column).

At first, we focus on four questions asked students in both schools that are directly related to our learning approach. We can see a statistically significant negative change in students feelings (we can see a drop from $90 \%$ to $55 \%$ at FEI STU and from $47.8 \%$ to $21.7 \%$ at SOS IT in terms of a number of students who agreed) that science/NEWTON lessons are really interesting. A similar situation can be seen in the case of the statement: Science/NEWTON lessons have made me more interested in STEM. Despite positive knowledge gain at both schools students interest in science classes decreased. Self-directed learning is still not very favourite learning approach for students of both levels. For a secondary level of students, console-based virtual labs (often used in learning networking subjects) do not always have to meet initial expectations and can be also found difficult to use. Students from technical universities are used to use similar labs but they also prefer classes to be more active. It can be seen a positive significant increase in feeling (requirement) for more activity in STEM lessons (statement: I would like STEM lessons to be more active). We can also notice a decrease in the attitude of university students that think that learning STEM is difficult. Despite decreased students interest (at both levels) in learning STEM after using NEWTON technologies, we find that students would prefer to learn using NEWTON technologies through the use of the virtual lab (an increase of $17 \%$ at FEI STU and $20 \%$ at SOS IT). After using NEWTON technologies students did not significantly change their opinion to the statement: I find learning STEM boring. Students at technical universities are used to work with labs, they also often have to work on projects themselves (alone) and the majority of them disagreed with this statement before the NEWTON pilot. The secondary level students could be discouraged by the SDL approach and some technical difficulties but on the other hand, they liked the virtual lab.

When we focus on feelings (engagement, anxiety, boredom, relaxation, sadness, happiness, anger, enjoyment) during learning (FEI STU students) we see that all feelings (except for enjoyment) became more positive (students expressed more disagreement with negative feelings and were much more positive in their positive feelings). Statistically significant increase was found for boredom, relaxation, and happiness. Many universitys students liked the freedom during the learning process and practising. Self-tests helped them to improve their knowledge. When considering students from SOS IT feelings like engagement and happiness reported significant positive change. These students were keen on using new technologies.

\subsection{Comparison of results for subgroups}

Within a deeper analysis of questionnaire results we gradually divided experimental groups into subgroups based on various criteria ( $e g$ what knowledge gain they achieved, if they like or dislike or have a neutral attitude to a school and learning STEM, etc). In this section, we evaluate results for those subgroups for the same questionnaire questions/statements. Because it would be too complex to analyse all subgroups for each school (FEI STU and SOS IT) and each question (Tab. 1) we only concentrate on a number of questions/statements students positively changed their attitude/feeling after NEWTON pilots (study). As was mentioned in the previous section, it means they expressed more disagreement with negative feelings and were much more positive in their positive feelings. Only subgroups with the highest number of questions with statistically significant positive changes are introduced below. 
Based on achieved knowledge gain (KG) we distinguished subgroups of students with KG higher than $42 \%$, between $14 \%$ and $30 \%$ and with zero or negative KG. We found out that university students with KG between $14 \%$ and $30 \%$ achieved the highest level of positive changes in their attitudes. They increased their relaxation and happiness feelings, they become more enthusiastic about their learning and they would like to have STEM lessons more active. However, they also significantly dropped in feelings that science lessons are really interesting. SOS IT (secondary level) students with KG higher than $14 \%$ increased their engagement feeling, happiness feeling or enthusiasm about their learning and feeling they want to learn with NEWTON technologies. However, students with KG between $14 \%$ and $30 \%$ do not want STEM lessons to be more active and they want less technology in learning STEM.

Subgrouping based on school attitude created subgroups of students who like/love school, students who do not like school and students with a neutral attitude (who said It is OK). The university students who answered about school that It's OK, reported the positive changes in their attitudes for the same questions as students with KG between $14 \%$ and $30 \%$. Moreover, they already do not think that learning STEM is so difficult. They also achieved statistically significant KG. However, they also significantly dropped in their interest in science classes. Subgrouping SOS IT students brought two groups (students who like/love school and who do not) with a few students (2-3) and the rest of the students (who said about a school that It's OK) showed the same results as the entire group of the SOS IT students. Similar subgroups like in the previous paragraph were formed based on students attitudes to learning STEM. The majority of university students answered that they like/love learning STEM, so we cannot make an evaluation based on this kind of subgrouping. However, in SOS IT students who do not like learning STEM didnt achieve significant positive knowledge gain but they reported a significant positive change for even 10 measured questions (highest from all various groups). On the other hand, the students who like/love learning STEM (significant KG) showed significant negative changes for 4 measured questions).

By focusing on students marks (grades) the students who get always or sometimes good marks in STEM reported a significant positive change in their feelings / attitudes for even 6 measured questions in both schools after entire pilots. In STU those questions are relaxation and happiness feelings, enthusiasm about their learning, learning with NEWTON technologies, and difficulty of STEM learning and level of activity in STEM lessons. In SOS IT those are engagement, relaxation, happiness and enjoyment feelings, enthusiasm about their learning and learning with NEWTON technologies. However, university students also disagreed that NEWTON has made them more interested in STEM whereas SOS IT students would like to use less technology in the classroom when they are learning STEM.
University students who play games achieved positive change for boredom and anger feelings, enthusiasm about their learning and learning with NEWTON technologies but negative change for their interest in science. University students who do not play games achieved positive change for relaxation and happiness feelings, enthusiasm about their learning and difficulty of STEM learning but their interest in science also decreased. SOS IT students who play games reported more positive changes (engagement, happiness, enthusiasm about their learning and learning with NEWTON technologies).

SOS IT students who do not use PC to do school work and homework showed significant positive change for 7 questionnaire questions and a negative change for no question. In the case of university students, the majority of them use PC for school work and homework.

\section{Discussion and conclusions}

In this paper, we presented results we acquired within two pilots (research studies) realised in the framework of the H2020 project NEWTON. These pilots were based on the integration of an (SDN/NFV) virtual lab with self-directed learning and its deployment to the learning process. Our main goal was focused on efficiency and usability investigation for this virtual lab based on learning in comparison with standard self-directed learning process. Pilots took place at Slovak university and secondary school where an experimental group of students learned using our virtual lab and a control group of students learned without that lab.

Authors in [35] tested their NVLab with 15 university students and achieved a positive knowledge gain. We decided to confirm this result with our Virtual lab and with Slovak university and secondary level students. Comparing knowledge acquisition of students in the experimental and control groups we can conclude that students that used developed virtual SDN/NFV lab during (selfdirected) learning process achieved considerably higher and statistically significant knowledge gain. University students showed even higher knowledge gain in comparison to secondary level students. University students are more used to work with similar systems and programs. On the other hand, students from the secondary school whose pilot took place sooner were exposed to a learning management platform (developed within the project) in the testing phase. Within this phase, some occasional instabilities of the platform could decrease their motivation to use other supporting elements (egself-tests) helping them to improve in a field.

Studies realised in $[34,35,41]$ showed a positive (satisfactory) feedback from students. Based on questionnaires taken by Slovak students before and after pilots, we can conclude that students of both schools would also like to learn using such virtual labs in their further learning process. On the other hand, students of both schools expressed that this type of learning did not make them more interested in STEM and they disagreed that science 
(NEWTON) lessons are really interesting. Self-directed learning is still a less favourite type of learning in comparison with a teacher-based learning scheme (in class). However, students liked the concept of virtual labs incorporated into the learning process because they allow them to make network experiments and assignments just using a PC or laptop. Well-prepared guides and manuals (for virtual lab), more user-friendly interfaces and a skilled instructor can markedly improve usability and learning efficiency of virtual labs (especially at secondary schools). Well-designed self-tests can also help students to improve their knowledge (and prepare them for the final exam).

None of realised studies performed deeper analysis, therefore, we also did an analysis of questionnaire results for student subgroups when the (both) experimental groups were divided into particular subgroups using various criteria. Finally, we could see what subgroups (students) have been positively influenced by technologies in pilots the most. Subgroups of universitys students with highest number of positive changes for questionnaire questions are subgroups of students with zero or negative knowledge gain (these students started with the highest level of knowledge and were very experienced in tested field), students who get always or sometimes good marks in STEM (these students are interested in a field and motivated to learn) and students who use PC (at home) to play games (probably these students are used to use computers in everyday life and for fun as well as working purposes). At secondary school such subgroups are subgroups of students with knowledge gain higher than $42 \%$ (these students started with a very low level of knowledge in a field and new technology attracted their interest), students who don't like learning STEM (technologyenhanced learning probably changed the attitude of these students to learn), students who get always good marks in STEM (students motivated to learn), students who don't use PC (at home) to play games and students who don't use PC to do school work and homework (quite the opposite situation to university students; integration of technology into education probably increased motivation of these students to learn a field).

The virtual SDN/NFV lab we developed can be ease integrated (and we already use it) in the educational process at the university level. It is based on standard server hardware and free software environments (OpenStack cloud platform, OpenDaylight SDN controller, Mininet network emulator, etc). Its application at secondary schools often faces and must overcome initial investments in necessary hardware. The OpenStack based platform allows developing virtual labs for training in various networking fields (testing communication protocols, network topologies, wireless networks, network security, etc) and institutions do not have to buy expensive specialized hardware.

Concept of virtual labs and their integration with (eg self-directed, problem-based, inquiry-based) learning should be tested and investigated further for various STEM subjects. Subgrouping analysis requires higher numbers of students in main groups and subgroups to acquire statistically significant results. It is also necessary to focus on the level of virtual lab adaptation for students at various levels of schools. It also relates to optimisation of user interfaces the students use for working in the virtual lab. Virtual labs enhanced by the virtual reality interface (in networking fields) also represent a subject for detailed analysis and study.

\section{Acknowledgements}

Research described in this paper was financially supported by the H2020 project NEWTON, No. 688503 and Erasmus+ project MOVET.

\section{REFERENCES}

[1] J. Playfoot, C. De Nicola, and F. Di Salvadore, "A New Experiential Model to Innovate the STEM Learning Processes", 11th International Technology Education Development Conference, pp. 4145-4153, 2017.

[2] A. E. Chis, A. N. Moldovan, L. Murphy, P. Pathak, and C. H. Muntean, "Investigating Flipped Classroom Problem-based Learning in a Programming Module for Computing Conversion Course", Educational Technology \& Society, vol. 21, no. 4, pp. 232-247, 2018.

[3] N. E. Mawas, I. Tal, A. N. Moldovan, D. Bogusevschi, J. Andrews, G. M. Muntean, and C. H. Muntean, "Final Frontier Game: A Case Study on Learner Experience", 10th International Conference on Computer Supported Education, vol. 2, pp. 122-129, 2018.

[4] E. Akgn and B. Akkoyunlu, "Instruction of computer supported collaborative learning environment students contribution quality", Procedia -Social Behavioral Sciences, vol. 9, no. 3, pp. 1489-1492, 2013.

[5] M. Shimba, M. P. J. Mahenge, and C. Sanga, "Virtual Labs versus hands-on labs for teaching learning computer networking: A comparison study", International Journal of Research Studies in Educational Technology, vol. 6, no. 1, pp. 43-58, 2017.

[6] V. Potkonjak, M. Gardner, V. Callaghan, P. Mattila, C. Guetl, V. M. Petrovic, and K. Jovanovic, "Virtual laboratories for education in science, technology", Computers \& Education, vol. 95, pp. 309-327, 2016.

[7] S. Loyens, J. Magda, and R. Rikers, "Self-directed learning in problem-based learning its relationships with selfregulated learning", Educational Psychology Review, vol. 20, pp. 411-427, 2008.

[8] K. Davidoff and C. Pieiro, "Project-Based Learning Self Directed Learning", 3rd International Conference on Higher Education Advances (HEAd17), pp. 1388-1395, 2017.

[9] K. Davidoff and C. Piñeiro, NEWTON H2020: Networked Labs for Training in Sciences Technologies for Information Communication Newton, 2016, [Online], Available: http://www.newton project.eu/.

[10] T. Lynch and I. Ghergulescu, "Review of Virtual Labs as the emerging technologies for teaching stem subjects", 11th International Technology Education Development Conference, pp. 6082-6091, 2017.

[12] L. Gomes and S. Bogosyan, "Current trends in remote laboratories", IEEE Transactions on Industrial Electronics, vol. 56, no. 12, pp. 4744-4756, 2009.

[13] G. Makransky, T. S. Terkildsen, and R. E. Mayerb, "Adding immersive Virtual Reality to a science lab simulation causes more presence but less learning", Learning Instruction, vol. 60, pp. 225-236, 2019. 
[14] J. Fröhlich and I. Wachsmuth, "Combining Multi-Sensory Stimuli in Virtual Worlds A Progress Report", International Conference on Virtual Augmented Mixed Reality, Designing Developing Virtual Augmented Environments, vol. 8525, pp. 44-54, 2014.

[15] S. Colbran and M. Schulz, "An update to the software architecture of the ilab service broker", Remote engineering virtual instrumentation international conference (REV), pp. 9093, 2015.

[16] C. Lorenzo, "Improving learning process through digital fabrication technologies", 9th International Conference on Education New Learning Technologies, pp. 6069-6076, 2017.

[17] The Labshare Institute http://www.labshare.edu.au.

[18] LRA http://lra.unileon.es.

[19] GoLab project https://www.golabz.eu.

[20] LiLa project http://www.lila-project.org.

[21] VccSSe project http://www.vccsse.ssai.valahia .ro/main/index?lang $=$ en.

[22] UNILabs https://unilabs.dia.uned.es.

[23] REX Controls https://www.rexcontrols.com/virtual-labs.

[24] "Virtual Laboratory Environment for Gear Train Design", Computer Applications in Engineering Education, vol. 22, no. 4, pp. 788-802, 2014.

[25] E. Aziz, Y. Chang, S. Esche, and C. Chassapis, VirtualCVD Reactor https://cbee.oregonstate. edu/education/VirtualCVD.

[26] C. Jara, F. Candelas, S. Puente, and F. Torres, "Hands on experiences of undergraduate students in automatics robotics using a virtual remote laboratory", Computers Education, vol. 57, no. 4, pp. 2451-2461, 2011.

[27] M. Hashemipour, H. F. Manesh, and M. Bal, "A modular Virtual Reality system for engineering laboratory education", Computers Applications in Engineering Education, vol. 19, no. 2, pp. 305-314, 2011.

[28] R. Lindgren, M. Tscholl, S. Wang, and E. Johnson, "Enhancing learning engagement through embodied interaction within a mixed reality simulation", Computers \& Education, vol. 95, pp. 174-187, 2016.

[29] A. Innocenti, "Virtual Reality experiments in economics", Journal of Behavioral Experimental Economics, vol. 69, pp. 71-77, 2017.

[30] P. Trúchly, M. Medvecký, P. Podhradský, and M. Vančo, "Virtual Reality Applications in STEM Education", 16th International Conference on Emerging eLearning Technologies Applications (ICETA), pp. 597-602, 2018.

[31] M. Cheng, Y. Lin, and H. She, "Learning through playing Virtual Age: Exploring the interactions among student concept learning, gaming performance, in-game behaviors", Computers \& Education, vol. 86, pp. 18-29, 2015.

[32] L. Xu, D. Huang, and W. T. Tsai, "Cloud-Based Virtual Laboratory for Network Security Education", IEEE Transactions on Education, vol. 57, no. 3, pp. 145-150, 2014.

[33] T. Arvind, "A comparative Study of Various Network Simulation Tools", International Journal of Computer Science \& Engineering Technology, vol. 7, no. 8, pp. 374-378, 2016.

[34] L. Xu, D. Huang, and W. T. Tsai, "V-Lab: A Cloud-based virtual lab-oratory Platform for Hands-on Networking Courses", 17th ACM annual conference on Innovation technology in computer science education (ITiCSE), pp. 256-261, 2012.

[35] M. Wannous and H. Nakano, "NVLab", IEEE Transactions on Learning Technologies, vol. 3, no. 2, pp. 129138, 2010.

[36] V. J. H. Powell, C. T. Davis, R. S. Johnson, P. Y. Wu, J. C. Turchek, and I. W. Parker, "VLabNet: The integrated design of hands-on learning In information security networking", 4th annual conference on Information Security Curriculum Development Conference (InfoSecCD), pp. 9:19:7, 2007.

[37] VIRL http://virl.cisco. com.

[38] EVE-NG http://www.eve-ng. com
[39] J. R. Brinson, "Learning outcome achievement in non-traditiona (virtual remote) versus traditional (hands-on) laboratories: A review of the empirical research", Computers \& Education, vol. 87, pp. 218-237, 2015.

[40] Z. Merchant, E. T. Goetz, L. Cifuentes, W. Keeney-kennicutt, and T. J. Davis, "Effectiveness of Virtual Reality-based instruction on students learning outcomes in K-12 higher education: A meta-analysis", Computers \& Education, vol. 70, pp. 2940 , 2014.

[41] L. Cui, F. P. Tso, D. Yao, and W. Jia, "WeFiLab: A Web-Based WiFi Laboratory Platform for Wireless Networking Education", IEEE Transactions on Learning Technologies, vol. 5, pp. 291-303, 2012.

[42] J. Londák, M. Medvecký, and P. Podhradský, "Virtual SDN NFV laboratory -architecture implementation", 59th International symposium ELMAR, pp. 197-200, 2017.

[43] M. Medvecký, R. Vargic, J. Londák, P. Podhradský, and P. Trúchly, "Integration of Virtual SDN NFV Laboratory with NEWTELP Platform", 60th International Symposium ELMAR, pp. 15-18, 2018.

Received 21 May 2019

Peter Trúchly (Ing, PhD) was born in Čadca, Slovakia, in 1972, is an assistant professor at the Slovak University of Technology, Faculty of Informatics and Information Technologies in Bratislava. He achieved his Masters degree in informatics in 1995 and $\mathrm{PhD}$ in applied informatics in 2004. He is interested in communication technologies, mobile applications and in the development of educational materials and e-learning platforms as well as their pilot testing.

Martin Medvecký (Doc, Ing, PhD), born in 1968 in Trenčín, Slovakia. He achieved his masters degree in the field of Telecommunications in 1991 and PhD in 1998 from Slovak University of Technology in Bratislava. Since 2009 he has been an associate professor at the Institute of Multimedia Information and Communication Technologies at the Faculty of Electrical Engineering and Information Technology, Slovak University of Technology in Bratislava. He is interested in communication technologies, network routing, virtualization, quality of service and network management.

Pavol Podhradský is a full professor in Telecommunications at the Slovak University of Technology in Bratislava and serves as a Deputy director of the Multimedia Information and Communication Technologies Institute, Faculty of Electrical Engineering and Information Technology. Born in Banská Štiavnica, Slovakia, in 1943, achieved his Master and PhD degree in telecommunications in 1965 and in 1980 at this university. He is interested in communication technologies, ICT network architectures and services, communication protocols as well as in the development of educational materials, also for e-learning.

Nour El Mawas received a PhD degree in Computer Science from the UTT at Troyes in 2013. She has been a postdoc at the Université du Maine, in design of instructional scenarios on learning management systems in the Graphit project. She was also a researcher in Telecom Bretagne, working on MOOCs personalization in a lifelong learning perspective in the European MOOCTAB project, and a researcher in the National College of Ireland. She proposed innovative pedagogical methods to teach STEM subjects in the European NEWTON project. Currently, Nour El Mawas is an Associate Professor at Université de Lille. 